\title{
Atividade in vitro de extratos brutos de duas espécies vegetais do cerrado sobre leveduras do gênero Candida
}

\author{
In vitro activity of crude extracts of two plant species \\ in the Cerrado on yeast of the Candida SPP variety
}

\author{
Sônia M aria Ferreira Queiroz e Silva ${ }^{1}$ \\ Sandra M aria Botelho Pinheiro ${ }^{1}$ \\ M aria Vilian Ferreira Q ueiroz ${ }^{1}$ \\ $M_{\text {aria Cristina Pranchevicius }}{ }^{1}$ \\ José Gerley Díaz Castro ${ }^{1}$ \\ Michele Cezimbra Perim ${ }^{1}$ \\ Solange Cristina Carreiro ${ }^{1}$
}

\footnotetext{
${ }^{1}$ Pró-Reitoria de Pesquisa e Pós-Graduação, Fundação Universidade Federal do Tocantins. ALC № 14, Avenida N S15, Bloco BALA Sala 19, Plano Diretor Norte. 77001-090 Palmas TO.propesq@uft.edu.br
}

\begin{abstract}
This work aims to evaluate the activity of Lafoensia Pacari and Brossimum gaudichaudii on yeast of the Candida variety isolated from vaginal mucus. The yeasts were obtained from swabs of women with or without symptoms. Susceptibility testing in duplicate was carried out for 34 strains of Candida compared to crude extracts of plant species at concentrations of 50, 100 and $200 \mathrm{mg} \cdot \mathrm{mL}^{-1}$. Extracts that produced inhibition zones with an average of over $10 \mathrm{~mm}$ were considered to be active. Antifungal activity of $B$. gaudichaudii at a concentration of 200- mg. mL ${ }^{1}$ was proven, while that of $L$. pacari wasfound to be active at $50 \mathrm{mg}^{\mathrm{mL}}{ }^{-1}$. The activity of plant extracts was revealed compared to $\mathrm{N}$ ystatin cream ( $100.000 \mathrm{U} / \mathrm{4g})$ used for control purposes. Key words Ethnobotany, Society, Alternative treatment, Candida

Resumo Objetivou-se conhecer a atividade de Lafoensia pacari e a de Brossimum gaudichaudii, sobre leveduras do gênero Candida isoladas da mucosa vaginal. As levedurasforam isoladas a partir deesfregaço demucosa vaginal de mulheres com ou sem sintomatologia. Realizou-se os testes de susceptibilidade em duplicata para 34 linhagens de Candida frente aos extratos brutos das espécies vegetais, nas concentrações de 50, 100 e $200 \mathrm{mg}^{\mathrm{mL}} \mathrm{H}^{-1}$. Consideraram-se como ativos os extratos que produziram halos de inibição com média a partir de $10 \mathrm{~mm}$. Evidenciou-se atividade antifúngica de $B$. gaudichaudii na concentração de $200 \mathrm{mg}^{\mathrm{mL}} \mathrm{L}^{-1}$, enquanto que a de L. pacari mostrou-se ativo a $50 \mathrm{mg}^{\mathrm{mL}}{ }^{-1}$. A atividade dos extratos vegetais estudados destacou-se em relação à N istatina creme $(100.000 \mathrm{U} / \mathrm{4g})$ utilizada como controle.

Palavras-chave Etnobotânica, Sociedade, Tratamento alternativo, Candida
\end{abstract}


Introdução

A História de plantas medicinais mostra que elas fazem parte da evolução humana sendo utilizadas como os primeiros recursos terapêuticos pelos povos. 0 registro desta história é de aproximadamente $10 \mathrm{mil}$ anos antes de Cristo. As primitivas civilizações perceberam, desde cedo, a existência de plantas comestíveis e de outras, não comestíveis, dotadas de poderes que ao serem consumidas, produziam sensações agradáveis e aliviavam as dores ${ }^{1,2}$.

O conhecimento sobre plantas medicinais simboliza muitas vezes o único recurso terapêutico de inúmeras comunidades e grupos étnicos. Ainda hoje são comercializadas em feiras livres, mercados populares e encontradas em quintais residenciais. Uma vez que as plantas medicinais são classificadas como produtos naturais, a lei permite que sejam comercializadas livremente, além de poderem ser cultivadas por aqueles que disponham de condições básicas necessárias ao plantio. Seu uso pela população mundial tem sido muito significativo nosúltimos tempos. Atualmente, dados da Organização M undial de Saúde (OMS) mostram que cerca de $80 \%$ da população mundial fez o uso de algum tipo de erva na busca de alívio de alguma sintomatologia dolorosa ou desagradável. Desse total, pelo menos $30 \%$ deu-se por indicação médica. Dessa forma, a OM S recomenda esta prática popular como forma de baixar os custos dos programas de saúde pública-5.

0 resgate de uso tradicional de plantas é conhecido como estudo etnobotânico e foi empregado pela primeira vez em 1895 por H arshberger. Esses estudos representam a área da pesquisa destinada à investigação das relações entre povos e plantas, destacando-se dentre essas relações, 0 estudo das práticas medicinais, envolvendo vegetais utilizados na medicina popular. Esse tipo de pesquisa muitas vezes tem proporcionado a produção de medicamentos com custos inferiores e, consequentemente, mais acessíveis à população que possam ser utilizados como parte do atendimento das necessidades primárias de saúde. Por isso, a etnobotânica trabal ha em estreita cumplicidade com a etnofarmacologia, que consiste na exploração científica interdisciplinar de agentes biologicamente ativos, Portanto, o resgate e a reval orização crescente da fitoterapia no Brasil atual exigem cuidados para que muitas plantas de importância medicinal não desapareçam das matas, da caatinga e do cerrado, antes mesmo queoscientistas descubram suas propriedades ${ }^{3,4,6}$.
O Cerrado é considerado como o mais antigo dos biomas, com cerca de 35 milhões de anos, de clima tropical, relevo pouco ondulado e tipicamentemarcado pela imensidão territorial com dois milhões dekm². É um bioma estratégico que possibilita uma relação com o pantanal, a floresta amazônica ea caatinga em virtude de sua ligação direta, como também é responsável por garantir o equilíbrio ecológico e a diversidade biológica destes biomas. Sendo caracterizado pela diversidade deespécies vegetais nativas, das adaptadas procedentes de outras regiões, de polinização de animais, pela resistência conjunta desses elementos e também pela diversidade química dessas espécies, ou seja, no cerrado existem valiosos componentes bioativos que podem ser considerados essenciais na defesa contra patógenos como também para a sobrevivência de suas espécies frequentemente expostas a variáveis condições de temperatura ${ }^{7-9}$.

Diversos vegetais têm sido utilizados com fins profiláticos e curativos de infecções. Atualmente muitos trabalhos vêm sendo realizados em busca de espécies com potencial antifúngico. Dentre estes se destacam os ensaios com plantas aromáticas por seus óleos essenciais serem reconhecidos empiricamente e pelas propriedades antimicrobianas demonstradas contra uma variedade de microrganismos. Neste sentido H eyder e Silva ${ }^{10}$ testaram o óleo volátil de Cymbopogon citratus (Poaceae) sobre Candida krusei e Candida parapapisilosi, e Chiapetta et al. ${ }^{11}$ testaram 0 extrato etanólico da folha de Lippia sidoides (Verbenaceae) frente a cepas de Candida sp isoladas do meio vaginal. A efetividadeantifúngica dos produtos destas espécies foi demonstrada através da inibição do crescimento das linhagens testadas.

A busca de propriedades antifúngicas da vegetação do cerrado com testagem de extratos brutos e/ou frações foram realizadas ${ }^{12}$ com a espécie Lafoensia pacari (Lithraceae) e com a Anacardium ocidentale (Anacardiaceae) sobre linhagens do gênero Candida ${ }^{13}$. N os respectivos estudos houve atividade antifúngica nas leveduras avaliadas. Kioto ${ }^{14}$ testou a Eugenia dysenterica (M yrtaceae) e a Annona crassiflora (Annonaceae) sobre leveduras do gênero Candida eCryptococus, e cujos extratos inibiram o crescimento destes patógenos, avaliou ainda a atividade da espécie Hi ptis suaveolens (Lamiaceae) que inibiu o crescimento de Candida albicans.

As leveduras do gênero Candida são fungos que ocorrem em todo o mundo, seja no solo, em plantas vivas ou mortas econvivem normalmente com o ser humano saudável em locais como 
pelee mucosas. Sendo uma levedura quese apresenta sob as formas de blastoconídeos, pseudohifas e/ ou hifas verdadeiras. 0 processo deidentificação das espécies de Candida baseia-se em aspectos morfológicos como aparência, cor etextura das colônias e em microscópicos como a produção de tubo germinativo e pseudo-hifas. Combinados com critérios bioquímicos característicos constituem-se importantes recursos para a determinação e/ou distinção entre as espécies C. albicans e C. não albicans ${ }^{15}$.

A infecção causada pelo gênero Candida é denominada candidose eacomete indivíduos em todo o mundo. Estes microrganismos apresentam-se como comensais ao homem, podendo ser oportunistas em certas ocasiões, habitam normalmente 0 aparel ho digestivo, respiratório, mucosa vaginal, oral e tegumento cutâneo. Seu espectro é bastante extenso, variando desde manifestações banais como a colonização de mucosas, até quadros sistêmicos com a invasão de vários órgãos. 0 diagnóstico clínico é sugerido pela presença de sintomas clássicos como pruridos, ardência, leucorreia e confirmado pelo diagnóstico laboratorial precedido da coleta de amostras da secreção vaginal. A terapêutica indicada compreende várias classes de medicamentos antifúngicos orais e tópicos ${ }^{15-18 .}$

Buscou-se como objetivo neste experimento, realizar um estudo etnobotânico para identificação de plantas medicinais tradicionalmenteutilizadas para infecções vaginais em usuárias da atenção básica atendidas na Policlínica 303 Norte de Palmas (TO) e verificar a eficácia in vitro de extratos brutos de duas espécies nativas frente a leveduras isoladas da mucosa vaginal ${ }^{19,20}$.

\section{Materiais emétodos}

A população participante do presente estudo compreendeu 60 mulheres com idades entre 18 a 65 anos cadastradas na Atenção à Saúde da M uIher da Policlínica 303 Norte no município de Palmas (TO), procedentes da zona urbana. A participação foi voluntária mediante assinatura de termo de consentimento livre e esclarecido. Como critério de inclusão na pesquisa utilizousea ausência de diabetes, degravidez, deHIV ede não estar sob terapêutica com corticosteróides e/ ou antifúngicos.

O presente estudo contou com a aprovação do Comitê de Ética em Pesquisa (CEP) da Universidade Luterana do Brasil (ULBRA).

\section{Levantamento Etnobotânico}

Para o levantamento etnobotânico foram realizadas entrevistas semiestruturadas, ocorridas na pré-consulta de Enfermagem, com a aplicação de questionário ${ }^{21}$. Foram obtidas informações sobre as plantas medicinais mais utilizadas pelas usuárias, partes usadas, modo de preparo, tempo e modo de uso, qual finalidade, seginecológico ou outros, conhecimento da(s) espécie(s), obtenção do conhecimento sobreessetipo detratamento e o resgate de saberes sobre o uso de plantas.

Isolamento das leveduras

Asleveduras foram isoladas a partir deamostras de mucosa vaginal coletadas utilizando-se swabs estéreis, por ocasião da coleta de exame citológico.

Cada swab foi semeado em placa de Petri contendo Ágar Sabouraud-dextrose acrescido de $0,02 \%$ de Cloranfenicol. As placas foram incubadas a $37^{\circ} \mathrm{C}$ em estufa bacteriológica por 48 horas. Após o período de incubação, as colônias foram purificadas por esgotamento utilizandose o mesmo meio. Todas as linhagens foram preservadas em meio Gymp sólido coberto com óleo mineral estéril, sob refrigeração, e em Gymp líquido acrescido deglicerol estéril a $-20^{\circ} \mathrm{C}$.

Caracterização morfológica

As amostras isoladas foram submetidas à caracterização morfológica através da observação dos aspectos macro e micromorfológicos. $\mathrm{Na}$ caracterização microscópica observou-se tamanho e forma das células, presença/ausência debrotamentos, clamidiosporos, pseudomicélio e tubo germinativo através da observação de lâminas a fresco sob microscopia óptica comum. Para a observação de tubo germinativo, colônias com 24 horas de crescimento em Ágar Sabouroud-dextrose foram semeadas em tubos de ensaio contendo $0,3 \mathrm{~mL}$ de soro humano suplementado com $0,5 \%$ de glicose com modificações ${ }^{15}$. Os tubos foram incubados em banhomaria a $37^{\circ} \mathrm{C}$ por 1 hora. Uma gota da suspensão foi analisada entre lâmina-lamínula sob microscópio óptico comum, para verificação da formação de tubo germinativo. Foram consideradas como $\mathrm{C}$. albicans as linhagens que apresentaram tubo germinativo, as demais foram consideradas como C. não albicans. 
Para análise da micromorfologia utilizou-se a técnica de microcultivo. As linhagens foram semeadas em estrias horizontais sobre o meio Ágar fubá (HIM ÉDIA) sobre lâminas de microscopia, dispostas em conjuntos estéreis. As lâminas foram incubadas em estufa a $37^{\circ} \mathrm{C}$ por 24 horas. Decorrido o tempo de incubação procedeu-se a observação sob microscopia óptica comum para verificação da presença de pseudohifas ${ }^{19}$.

Avaliação da atividade dos extratos in vitro

Dentre as plantas com finalidade terapêutica para candidose vaginal citadas pelas usuárias foram selecionadas 02 espécies botânicas por serem nativas do cerrado, considerando a disponibilidade destas espécies no entorno da cidade de Palmas. As espécies selecionadas foram Lafoensia pacari (Pacari) e Brossimum gaudichaudii (Inharé).

\section{Obtenção dos extratos brutos}

Os extratos brutos foram obtidos a partir de entrecascas por maceração em etanol após secagem em estufa a $40-60^{\circ} \mathrm{C}$ por $36 \mathrm{~h}$ segundo a metodologia proposta por Oliveira ${ }^{20}$. A preparação incluiu $500 \mathrm{~g}$ do pó em 01L de etanol a 95\% em becker tampado com filme PVC. Após 48 horas o material foi filtrado em coador de papel e posteriormente levado ao evaporador rotativo marca FISATON (modelo 803) regulado para 60 rpm e $45^{\circ} \mathrm{C}$ para extração do solvente. Após 02 horas o material foi colocado em estufa atécompleta secagem. Os extratos brutos obtidos foram acondicionados em frascos âmbar estéreis e congelados até o momento do uso.

Obtenção do inóculo

0 inóculo foi preparado pela suspensão das colônias em $02 \mathrm{~mL}$ de solução salina a 0,85\% estéril a partir de um cultivo de 24 a 48 horas. A suspensão foi padronizada em espectrofotômetro marca BIOSPECTRO SP-22 calibrado a 625 nm, com absorbância ajustada à 0,08 a 0,10 , que corresponde a 0,5 da escala de M c Farland ${ }^{21}$.

Teste de susceptibilidade in vitro

Os testes de susceptibilidade foram realizados em duplicata através da técnica de difusão em poços, utilizando-se meio Agar-SabouroudDextrose adicionado $0,02 \%$ de cloranfenicol. Os meios foram estriados com swabs estéreis umedecidos com a suspensão do inóculo. Em seguida foram perfurados 08 poços de $06 \mathrm{~mm}$ de diâmetro, com o auxílio de ponteira estéril. Cada poço foi preenchido com $50 \mu$ l dos extratos vegetais em 03 diferentes concentrações: $200 \mathrm{mg} / \mathrm{mL}$, $100 \mathrm{mg} / \mathrm{mL}$ e $50 \mathrm{mg} / \mathrm{mL}$. Para o controle positivo utilizou-se N istatina cremevaginal $1.000 \mathrm{UI} / 4 \mathrm{mg}$ genérica (Prati Donaduzzi) e para o controlenegativo salina estéril $(0,85 \%)$. As placas foram incubadas a $37^{\circ}$ por 48 horas procedendo-sea primeira leitura destas placas após 24 horas e a segunda leitura com 48 horas da incubação. Considerou-se como parâmetro de atividade a presença ou a ausência de halos de inibição do crescimento formados em volta dos poços. Os halos foram medidos com o auxílio de uma régua milimetrada, sendo o resultado dado pela média aritmética da soma dos halos formados na segunda leitura em cada duplicata verdadeira

$$
M \text { halo }=\frac{(Y 1-X 1)+\left(Y 2-X_{2}\right)}{2} .
$$

Foram considerados positivos aqueles com diâmetro igual ou superior a $10 \mathrm{~mm}^{22-24}$.

\section{Análise estatística}

As análises dos dados experimentais incluíram o teste Exato de Fischer para comparar a frequência de linhagens sensíveis e resistentes entre as espécies dentro de cada uma das diluições estudadas. 0 teste de Linearidade foi utilizado para verificar a relação entre a concentração e a eficácia das diluições. 0 teste de F de ANOVA, com teste a posteriori de Tukey, foi utilizado para comparar as diferentes diluiçõeseo controlepara cada espécie vegetal considerando-se o diâmetro médio dos halos de inibição. 0 teste de " $t$ " de Student para variâncias heterocedásticas foi feito para comparar as espécies dentro de cada diluição. Todos os testes foram feitos considerando $5 \%$ de probabilidade. As análises foram feitas com o auxílio dos pacotes estatísticos Epi Info, versão 2.0, 3.5.1 e Bioestat versão 5.0.

\section{Resultados ediscussão}

I solamento e caracterização morfológica das leveduras

No intento deconhecer o perfil depositividadepara o gênero Candida realizou-seisolamento e identificação preliminar das leveduras a partir de esfregaço vaginal das usuárias consideradas sintomáticas ou não ao exame clínico. Das 60 amostras de esfregaço vaginal obtidas, 50 apresentaram crescimento de leveduras, o que mostra $67 \%$ de positividade para estas. 10 linhagens 
perderam a viabilidade após período de estocagem e, portanto, a caracterização morfológica foi realizada com 40 linhagens.

0 aspecto macroscópico mostrou colônias de coloração branca a creme, aspecto liso com ou sem brilho, características do gênero Candida. A formação de pseudo-hifas foi observada em 15 amostras, porém essa característica isoladamente não permite a diferenciação de C. albicans eC. não al bicans. A presença detubo germinativo foi observada em $25(62,5 \%)$ dos isolados, caracterizando-os assim como C. albicans, já que a formação de tubo é característica dessa espécie. Portanto, as 25 amostras que produziram tubo germinativo foram identificadas como Candida albicans, enquanto que as 15 amostras restantes que exibiram estrutura características depseudomicélio foram identificadas como Candida não albicans, segundo a literatura ${ }^{15,17,19}$.

Vale considerar que a prova do tubo germinativo apresenta alta especificidade, apresentando índice positivo entre 94 a $97 \%$. Já a prova da formação de pseudomicélio, que se baseia no princípio de que as leveduras quando incubadas num meio com baixa tensão de oxigênio, tem a capacidade de filamentar, constitui-se em parâmetro morfológico apenas para agrupar leveduras não albicans, não sendo pois determinante na distinção das respectivas espécies ${ }^{15,18}$.

A tentativa de se estabelecer a pertinência da colonização por Candida ao compartimento clínico eterapêutico da can didosevulvovaginal temse direcionado estudos que buscam estabelecer a importância da quantidade e da qualidade do processo de colonização para a compreensão dos aspectos de virulência da Candida, destacada com base no conhecimento das espécies. Para tanto, as investigações acerca da identificação das espé cies de Candida situando a prevalência de positividade deste gênero nos isolados têm demonstrado a prevalência de C. albicans, assim como têm apontado e destacado as C. não albicans pelo surgimento de resistência aos antifúngicos ${ }^{16}$. Estes achados corroboram com os nossos dados que apontaram a C. albicans em $62,5 \%$ dos isolamentos e 38\% C. não albicans.

\section{Atividade in vitro de extratos vegetais}

Com referência às atividades das espécies ve getais do cerrado selecionadas, os resultados obtidos neste estudo revelaram a atividade inibitória dos extratos de L. pacari eB. gaudichaudii, comparados com a N istatina creme vaginal (Prati Donaduzzi - $1000 \mathrm{UI} / 4 \mathrm{mg}$ ), sobre o crescimento de leveduras do gênero Candida. As médias dos halos de inibição estão descritas na Tabela 1.

O bserva-se através do resultado da Tabela 1 que os extratos de L. pacari nas três concentrações testadas apresentaram atividade antifúngica caracterizada pela formação de halos de inibição superiores a $10 \mathrm{~mm}$ em 21 (vinte e uma) cepas de C. albicans testadas, formando, inclusive halo de $18 \mathrm{~mm}$. Percebe-se maior atividade deste extrato em relação ao controleNistatina, cujo halo máximo foi de $11 \mathrm{~mm}$. Os extratos de B. gaudichaudii tiveram efetividade na concentração de $200 \mathrm{mg} /$ $\mathrm{mL}$, apresentando halos de inibição com diâmetro máximo de $11 \mathrm{~mm}$. A espécie vegetal L. pacari, foi efetiva em todas as concentrações estudadas, diferentemente de B. gaudichaudii que o foi somente na maior concentração utilizada.

$\mathrm{Na}$ Tabela 2 observa-se que os extratos de L. pacari e B. gaudichaudii nas mesmas concentrações sobre espécies $C$. não albicans, em que se observou a atividade de L. pacari já a partir da menor concentração testada, com formação de halos na sua maioria superiores a $10 \mathrm{~mm}$ e na maior concentração apresentou atividade expressiva sobre todas as linhagens exibindo halos que variaram de 11 a $15 \mathrm{~mm}$. Por outro lado, B. gaudichaudii demonstrou alguma atividade a partir da concentração de $100 \mathrm{mg} / \mathrm{mL}$ evidenciou atividade interessante na maior concentração, cujos halos variaram em sua maioria de $11 \mathrm{~mm}$ a 12 $\mathrm{mm}$, enquanto que a Nistatina apresentou atividadeem apenas 6 (seis) das 13 (treze) cepas deC. não albicans incluídas no estudo formando halos de inibição entre 10 e $11 \mathrm{~mm}$.

Comparando a média dos halos de inibição produzidos foi possível constatar que em ambas as espécies C. albicanseC. não albicans testadas, a menor concentração de L. pacari apresentou atividade antifúngica, e ainda que $B$. gaudichaudii demonstrou atividadeantifúngica superior $\mathrm{a} \mathrm{N}$ istatina na maior concentração, demonstrando mais efetividade nas espécies não albicans. Esses dados são rel evantes na medida em que a espécie C.albicans e C. glabrata (não albicans) apresentam resistência aos antifúngicos convencionais ${ }^{13}$.

No que se refere a fitoquímica de L. pacari, a literatura científica aponta mais estudos sobre a casca e folha. Sendo que sobre a primeira, indicam a presença marcante de áci do elágico etaninos $^{24}$. A amplitude dos efeitos biológicos benéficos aponta para o ácido elágico presente na casca quefaz deL. pacari uma importantefonte medicinal. M esmo havendo inúmeras e complexas substâncias químicas nessa espécie vegetal, a comparação das atividades terapêuticas do áci- 
Tabela 1. M édia do diâmetro dos halos de inibição $(\mathrm{mm})$ dos extratos vegetais sobre as linhagens de Candida albicans.

\begin{tabular}{|c|c|c|c|c|c|c|c|}
\hline \multirow{3}{*}{ Linhagens } & \multicolumn{6}{|c|}{ Espécie vegetal } & \multirow{3}{*}{$\begin{array}{l}\text { Controle } \\
\text { Nistatina }\end{array}$} \\
\hline & \multicolumn{3}{|c|}{ L. pacari } & \multicolumn{3}{|c|}{ B. gaudichaudii } & \\
\hline & $200 \mathrm{mg} / \mathrm{mL}$ & $100 \mathrm{mg} / \mathrm{mL}$ & $50 \mathrm{mg} / \mathrm{mL}$ & $200 \mathrm{mg} / \mathrm{mL}$ & $100 \mathrm{mg} / \mathrm{mL}$ & $50 \mathrm{mg} / \mathrm{mL}$ & \\
\hline 02 & 18 & 12 & 12 & 09 & 08 & 08 & 11 \\
\hline 08 & 13 & 12 & 09 & 08 & 08 & 07 & 09 \\
\hline 14 & 12 & 12 & 10 & 09 & 07 & 07 & 09 \\
\hline 19 & 12 & 11 & 10 & 08 & 07 & 07 & 08 \\
\hline 20 & 13 & 12 & 11 & 10 & 09 & 07 & 10 \\
\hline 22 & 14 & 13 & 12 & 11 & 09 & 06 & 09 \\
\hline 23 & 13 & 11 & 11 & 11 & 07 & 07 & 09 \\
\hline 24 & 14 & 12 & 11 & 10 & 09 & 07 & 08 \\
\hline 25 & 12 & 12 & 11 & 11 & 08 & 08 & 09 \\
\hline 26 & 16 & 14 & 13 & 10 & 07 & 06 & 11 \\
\hline 27 & 16 & 13 & 12 & 11 & 07 & 07 & 07 \\
\hline 28 & 13 & 13 & 12 & 09 & 09 & 06 & 09 \\
\hline 29 & 14 & 13 & 11 & 10 & 09 & 08 & 09 \\
\hline 30 & 18 & 14 & 14 & 11 & 09 & 06 & 07 \\
\hline 31 & 13 & 11 & 10 & 10 & 07 & 07 & 11 \\
\hline 32 & 14 & 12 & 11 & 08 & 08 & 09 & 08 \\
\hline 33 & 15 & 12 & 11 & 10 & 08 & 06 & 09 \\
\hline 42 & 14 & 14 & 13 & 11 & 09 & 07 & 10 \\
\hline 43 & 12 & 10 & 10 & 10 & 08 & 07 & 11 \\
\hline 44 & 12 & 12 & 11 & 10 & 07 & 07 & 10 \\
\hline 45 & 14 & 14 & 10 & 09 & 08 & 07 & 07 \\
\hline
\end{tabular}

Tabela 2. M édias de diâmetros dos halos nos testes de susceptibilidade para as espécies não al bicans.

\begin{tabular}{|c|c|c|c|c|c|c|c|}
\hline \multirow{3}{*}{ Linhagens } & \multicolumn{6}{|c|}{ Espécie vegetal } & \multirow{3}{*}{$\begin{array}{l}\text { Controle } \\
\text { Nistatina }\end{array}$} \\
\hline & \multicolumn{3}{|c|}{ L. pacari } & \multicolumn{3}{|c|}{ B. gaudichaudii } & \\
\hline & $200 \mathrm{mg} / \mathrm{mL}$ & $100 \mathrm{mg} / \mathrm{mL}$ & $50 \mathrm{mg} / \mathrm{mL}$ & $200 \mathrm{mg} / \mathrm{mL}$ & $100 \mathrm{mg} / \mathrm{mL}$ & $50 \mathrm{mg} / \mathrm{mL}$ & \\
\hline 01 & 13 & 11 & 09 & 09 & 08 & 08 & 11 \\
\hline 07 & 15 & 12 & 11 & 09 & 09 & 06 & 11 \\
\hline 09 & 15 & 13 & 11 & 12 & 08 & 08 & 10 \\
\hline 10 & 13 & 13 & 11 & 11 & 09 & 08 & 09 \\
\hline 38 & 11 & 10 & 10 & 09 & 09 & 07 & 08 \\
\hline 39 & 13 & 13 & 12 & 12 & 10 & 07 & 10 \\
\hline 40 & 12 & 11 & 11 & 11 & 06 & 06 & 08 \\
\hline 41 & 14 & 11 & 11 & 10 & 08 & 07 & 12 \\
\hline 46 & 14 & 13 & 12 & 10 & 08 & 08 & 09 \\
\hline 47 & 14 & 12 & 12 & 12 & 10 & 09 & 07 \\
\hline 48 & 13 & 11 & 10 & 11 & 07 & 07 & 11 \\
\hline 49 & 12 & 10 & 07 & 10 & 08 & 06 & 09 \\
\hline 50 & 11 & 10 & 10 & 12 & 10 & 06 & 08 \\
\hline
\end{tabular}

do elágico com o uso medicamentoso da casca de L. pacari sugerem a atuação dessa substância como principal composto químico ativo ${ }^{25,26}$ que também analisaram a presença ea sensibilidadede seus fitoconstituintes químicos.
Pires et al. ${ }^{27}$ obtiveram compostos a partir da casca, e demonstraram atividade positiva sobre C. albicans e os extratos da folha foram ativos sobre Candida albicans. A potente ação antibacteriana do extrato hidroalcoólico de L. pacari 
contra bactérias multi rresistentes de origem hospitalar foi registrada por M elo-Filho et al. ${ }^{28}$.

Estudos realizados com extrato hidroalcoólico da L. pacari indicaram a presença detaninos, esteróides, flavonoides, terpenos e saponinas ${ }^{12}$. Outras pesquisas, também confirmaram na análise preliminar qualitativa o papel que os flavonóides desempenham na biologia vegetal, que é, por vezes, aproveitado para explorar suas atividades terapêuticas como, por exemplo, antifúngica e bactericida, antioxidante e protetora dos raios ultravioleta ${ }^{29}$.

Pozetti ${ }^{30}$ testou concentrações de 25 e $50 \mathrm{mg}$ deextratos hidroal coólicos deB. gaudichaudii em cepas de bactérias e $C$ andida albicans, não houve atividade antimicrobiana. No mesmo estudo foram isolados substâncias químicas como as cumarinas, dentre estas o psoraleno, o bergapteno, a umbeliferona ea hidroximarmesina, 0 psoraleno eo bergapteno exercem ação contra o vitiligo. Outras aplicações terapêuticas são possíveis para o psoraleno e seus derivados, tais como em micoses, casos de urticária, psoríases, alopecia areata, herpes simples, algumas parasitoses humanas ou animais, além de outras dermatoses.

\section{Colaboradores}

SM FQ Silva desenvolveu o projeto de pesquisa, atuou na coleta dos dados e na redação do texto. SM B Pinheiro contribui com a correção de texto escrito e com a definição da parte farmacêutica do projeto. MVF Queiróz contribuiu com a orientação do projeto ea coleta de dados. M C Pranchevicius auxiliou na elaboração do projeto e na escrita dos resultados. JGD Castro contribuiu com a análise estatística dos dados e a redação do artigo final. MC Perim contribuiu na execução dos experimentos. SC Carreiro atuou em todas as etapas do projeto como orientadora da autora principal.

\section{Conclusão}

Os resultados obtidos mostraram que a espécie $C$. albicansfoi predominante, representando $62,5 \%$ do total de isolados. Os extratos brutos da L. pacari apresentaram um largo espectro de ação nas três concentrações testadas contra ambos os grupos, C. albicans e C. não albicans; já os extratos brutos de B. gaudichaudii foram efetivos contra C. albicans apenas na concentração de $200 \mathrm{mg} /$ $\mathrm{mL}$ e contra $\mathrm{C}$. não albicans nas concentrações de $100 \mathrm{mg} / \mathrm{mL}$ e $200 \mathrm{mg} / \mathrm{mL}$. Esses resultados mostram-se promissores e apontam para a necessidade de estudos mais abrangentes visando à purificação das frações dos extratos obtidos a partir das espécies vegetais estudadas, além de outras espécies nativas do cerrado, e à verificação de sua eficácia contra outras linhagens do gênero Candida.

Sugere-se ainda estudos envolvendo a terapêutica antifúngica quanto à efetividade, reações adversas e toxicidade, o que poderá contribuir para a orientação de ações e estratégias de apoio eincorporação das plantas medicinais nas práticas em serviços de Atenção à Saúde da M ulher.

\section{Referências}

1. Tomazzoni MI, Negrelle RRB, Centa ML. Fitoterapia Popular: A busca instrumental enquanto prática terapêutica. Texto \& Contexto Enfermagem 2006; 15(1):115-121.

2. Boscolo $\mathrm{OH}$, Valle LS. Plantas de uso medicinal em Quissamã, Rio de Janeiro, Brasil. Iheringia 2008; 63(2):263-277.

3. Maciel MAM, Pinto AC, Veiga Júnior VF. Plantas $M$ edicinais: A necessidade de estudos multidisciplinares. Química Nova 2002; 25(3):429-438.

4. Lopez CAA. Considerações gerais sobre plantas medicinais. Ambiente, Gestão e Desenvolvimento 2006; 1(1):19-27.

5. Brasil. M inistério da Saúde (MS). Secretaria de Ciência, Tecnologia e Insumos Estratégicos. Departamento de Assistência Farmacêutica. A Fitoterapia no SUS e o Programa de Pesquisas de Plantas M edicinais da Central de M edicamentos. Brasília: M S; 2006.

6. Coutinho DF, Travassos LMA, Amaral FM M. Ethnobotanical study of Medicinal Plants used by the Indian communities from M aranhão - Brazil. Visão Acadêmica 2002; 3(1):7-12.

7. Guarim Neto G, Morais RG de. Recursos medicinais de espécies do cerrado de M ato Grosso: Um estudo bibliográfico. Acta Botânica Brasileira; 4(17):561-584. 
8. Pereira WV, Papa M FS. Antifungal activity of differents parts of Lafoensia pacari on Corynespora cassicola and Colletotrichum gloeosporioides [página na Internet]. [acessado 2009 ago 29]. Disponível em: http://www.instrutor.com.br/unesp2006/premiados/ wagnervicente.pdf

9. N ascimento JB. Cerrado: Nosso bioma, nossa riqueza. 1a ed. Palmas: Kelps; 2007.

10. Heyder CDT, Silva DAK. Avaliação da atividade antifúngica do óleo volátil de Cymbopogon citratus sobre Candida krusei e Candida parapapilosis. Revista Saúde e Ambiente 2004; 5(2).

11. Chiapetta AA, Sena KXFR, Higino JS, Sousa IA, Farias EM FG, Albuquerque JFC.Estudo de componentes químicos e atividade antifúngica de Lippia sidoides Cham. (Verbenaceae) contra diferentes espécies de candida. In: 25a. Reunião Anual da Sociedade Brasileira de Química; 2002; Poços de Caldas (MG). Resumos.

12. M undo SR. Caracteres M orfo-anatômicos de folha e caule de Espécies brasileiras de uso medicinal: Calophyllum brasiliense Cambess. (Clusiaceae), Cupania vernalis Cambess. (Sapindaceae) e Lafoensia pacari A. St.-Hil. (Lythraceae) [dissertação]. Curitiba (PR): Universidade Federal do Paraná; 2007.

13. Costa $A C B P$, Pereira $C A$, Freire $F$, Junqueira JC, Jorge $A O C$. Atividade antifúngica de extratos glicólicos de Rosmarinus officinalis Linn. e Syzygium cumini Linn. sobre cepas clínicas de Candida albicans, Candida glabrata e Candida tropicalis. Rev Odontol UNESP 2009; 38(2):111-116.

14. Kioto LAS. Propriedades antimicrobianas de plantas do cerrado sobre dermatófitos [dissertação]. Goiânia (GO): Universidade Federal de Goiás; 2002.

15. Sidrim JJC, Moreira JLB. Fundamentos Clínicos e Laboratoriais da Micologia M édica. Rio de Janeiro: Guanabara; 1999.

16. Prevalência e susceptibilidade de leveduras vaginais. Jornal Brasileiro de Patologia M édica Laboratorial 2004 ago; p. 229-236.

17. Conceição $G C$, Coelho $P P$, Sousa Júnior $M A$ de, Pereira ML, Miguel DSCG, Toralles M BP. Avaliação do Tubo Germinativo em secreção vaginal a fresco para triagem de Candida albicans: Um teste rápido. Rev N ewsLab 2005; (73):106-112.

18. Camargo FP, Alves IA, Parlow MS, Goulart LS. Isolamento de Candida sp da mucosa vaginal de muIheres atendidas em um serviço de ginecologia do município de Santo Ângelo-RS. Rev N ewsLab 2008; 87:96-104.

19. Fischer F, Cook NB. Micologia Fundamentos e Diagnóstico. Rio de Janeiro: Revinter; 2001.

20. Oliveira RAG. Plantas M edicinais usadas tradicionalmente na Dermatologia: Avaliação da atividade biológica de seus extratos, óleos essenciais e suas associações [tese]. João Pessoa (PB): Universidade Federal da Paraíba; 2006.
21. Lima EO, Belém LF, Cechinel Filho V, Corrêa RN, Nunes RJ, Andricopulo A, Silva VE da. Avaliação da sensibilidade de cepas de Malassezia furfur a imidas cíclicas. Rev. Bras. Cienc. Farm. 2002; 38(4): 443-450.

22. Kruger, M. F. Controle de Listeria monocytogenes na lingüiça frescal refrigerada através do óleo essencial de orégano e nisina [dissertação]. São Paulo (SP): Universidade de São Paulo; 2006.

23. Tamashiro Filho P, Martins DTO. Avaliação da atividade Anti-úlcera do extrato bruto metanólico (EM LP) de Lafoensia pacari St. Hil. (Lythraceae). In: Federação de Sociedades de Biologia Experimental (FeSBE); 1998; Caxambú (M G). p. 67-12.

24. Antunes RMP, Lima EO, Pereira MSV, Câmara CA, Arruda TA, Catão RM R, Barbosa TP, Nunes SP, Dias CS, Silva TMS. Atividade antimicrobiana in vitro e determinação da Concentração Inibitória M ínima (CIM) de Fitoconstituintes e produtos sintéticos sobre bactérias e fungos leveduriformes. Rev. Bras. Farmacogn. 2006; 16(4):517-524.

25. Braga LG, Solon S. O gênero Lafoensia vandeli: revisão bibliográfica com ênfase nos aspectos etnobotânicos, fitoquímicos e farmacológicos de Lafoensia pacari St. Hil. (Lythraceae). Rev. NEO grafias 2005; 17:49-59.

26. Lima MRF de, Luna J de S, Santos AF dos, Andrade MCC de, Sant'Ana AEG, Gennet J-P, M arquez B, Neuville L, M oreau N. Anti-bacterial activity of some Brazilian medicinal plants. J. ethnopharmacol 2006; 105(1-2):137-147.

27. Pires LL, Lima M RF, Araújo CWG, Porfírio Z. Avaliação da atividade antimicrobiana de frações de Lafoensia pacari Saint. Hil - Lythraceae em linhagens de microrganismos patogênicos humanos. In: Jornada Científica de Farmácia; 2003; M aceió (AL). p. 24-5.

28. M elo-Filho GC, Lima M RF de, Porfírio Z. Estudo da atividade antibacteriana de extrato hidroalcoólico de Lafoensia pacari (Saint Hil.) contra bactérias multiresistentes de origem hospitalar. In: Jornada Científica de Farmácia; 2003; M aceió (AL). p.38-37.

29. Violante IMP, Sousa IM, Venturini $C L$, Ramalho AFS, Santos RAN, Ferrari M. Avaliação in vitro da atividade fotoprotetora de extratos vegetais do cerrado de Mato Grosso. Rev. Bras. Farmacogn. 2099; 19(2):452-457.

30. Pozetti GL. Brosimum Gaudichaudii Trcul (Moracease): da planta ao medicamento. Rev. Ciênc. Farm. Básica Apl. 2005; 26(3):159-166.

Artigo apresentado em 30/11/2011

A provado em 05/03/2012

Versão final apresentada em 15/03/2012 